\title{
The Use of the Cavitation Effect in the Mitigation of $\mathrm{CaCO}_{3}$ Deposits
}

\author{
David Heath 1 - Brane Širok ${ }^{2}$ - Marko Hočevar2,* - Boštjan Pečnik1,3 \\ ${ }^{1}$ MPŠ Jožef Stefan International Postgraduate School, Slovenia \\ 2 University of Ljubljana, Faculty of Mechanical Engineering, Slovenia \\ ${ }^{3}$ Gorenje d.d., Slovenia
}

\begin{abstract}
Hard mineral scale fouling results in significant economic losses both industrially and domestically. Recently, attempts have been made to use ultrasound to mitigate scale formation and its removal based on the phenomena of cavitation. Cavitation erosion is the removal of material from a solid surface by pressure shock waves associated with the formation and collapse of bubbles. This paper reviews the literature on cavitation erosion of brittle crystalline materials in an attempt to better understand the relationship between the material properties of $\mathrm{CaCO}_{3}$ scale deposits and its potential removal by cavitation. The study finds that from a materials perspective cavitation erosion is intimately associated with both a material's bulk properties and importantly to its microstructure. The situation is further complicated because the macro and micro-properties of $\mathrm{CaCO}_{3}$ scale are dependent on many factors relating to its depositional environment. The type of scale formed will affect how it is removed by cavitation.
\end{abstract}

Keywords: cavitation, cavitation erosion, ultrasound, scale, calcium carbonate

\section{INTRODUCTION}

The build-up of $\mathrm{CaCO}_{3}$ (lime) scale is a major operational headache that affects a range of industrial processes including membrane filtration (desalination), drilling, and especially those that involve heat transfer. In a heat exchanger the effects are twofold: first, even a small coating of scale can significantly reduce heat transfer efficiency and second, by acting as an insulator, it will cause a heating element to get much hotter internally leading to component failure. Scale can also drastically reduce the flow in pipes. In the domestic setting, in areas affected by hard water, home appliances like boilers, washing machines, and solar collectors are prone to scale build-up and, just as in industry, it can reduce performance and working life. Additional consequences are increased service charges, frequent equipment replacement, and higher energy bills - up to $25 \%$ more [1]. The costs incurred in preventing and remedying scale both industrially and domestically are considerable. According to Müller-Steinhagen et al. [2], the total annual cost due to fouling for highly industrialized countries, such as the United States or the United Kingdom are about $0.25 \%$ of their Gross National Product (GNP). These figures may only be indicative, but they underline the significant impact that scale has on global energy efficiency [3]. The percentage of energy losses due to fouling is at least $2 \%$ globally. Another way of estimating the size of the problem is by looking at how much is spent on preventing scale. Scale inhibitors are the third largest product segment of the water treatment chemicals market (corrosion inhibitor market being the largest) and by 2016 will be worth an estimated $\$ 3.6$ billion [4].

Scale management ideally is about the prevention of scale and currently the most efficient way to prevent scaling is by using chemical inhibitors or descalers. Chemicals, however, are costly and their environmental impact is questionable, which has led to the search for both cheaper and "greener" alternatives [5]. They include "natural" chemical agents, surface treatments including coatings, and magnetic and electronic conditioning, all of which show varying degrees of efficacy (Table 1). Once formed, the removal of a tenacious scale involves either chemical (acid) treatment to dissolve the scale or some form of mechanical removal [6]. The main benefit of using a mechanical method is that it avoids the use of chemicals, but where this has to be done by hand, it can be time consuming and costly. An alternative approach is the possible use of ultrasound. Ultrasonic cleaning is a well-established and efficient technology particularly for dislodging solid residues and removal of biological fouling. It is also the bestknown application of acoustic cavitation. Cavitation is the phenomena of the rapid formation and implosion of bubbles in an area of low-pressure in liquids by means of mechanical forces [7] and [8].

The aim of this paper is to present a literature review in relation to existing studies involving ultrasonically induced cavitation for the mitigation and, importantly, the removal of tenacious $\mathrm{CaCO}_{3}$ deposits. Fortunately, a large corpus of literature now exists on both scale formation and cavitation 
phenomena including mechanisms of cavitation erosion. From an initial survey of the literature it becomes readily apparent that cavitation erosion is intimately associated with material bulk properties and microstructure and therefore this topic is best researched from a materials science perspective. It is essential to review published studies that develop our understanding of the bulk macro- and micro-structural surface properties of scale and the cavitation erosion of brittle crystalline materials.

Table 1. The effectiveness of different scale treatments. Adapted from [9]

\begin{tabular}{lc}
\hline Scale treatment & Effectiveness (\% reduction) \\
\hline lon exchange & 100 \\
\hline Acid dosing & 100 \\
\hline Chemical inhibitors & 100 \\
\hline Metal ions & 80 \\
\hline Magnetic conditioners & 80 \\
\hline Electronic conditioners & 80 \\
\hline Electrolytic & 40 \\
\hline Ultrasound & 30 \\
\hline Surface modifications & 90 \\
\hline
\end{tabular}

\section{SCALE FORMATION}

Calcium carbonate is atypical in that it is a reverse solubility salt, i.e. solubility decreases with increasing temperatures and hence is a fouling nuisance in heating equipment in areas of high water hardness. Generally, exceeding the solubility of a particular salt will initiate scale formation, albeit the actual process is complex and depends on many factors including supersaturation level, fluid composition, temperature, flow regime, and surface properties like surface energy and roughness [9] and [10]. When $\mathrm{CO}_{2}$ dissolves in water, it forms a weak carbonic acid, which dissociates into hydrogen carbonate, hydrogen, and carbonate ions. Calcium ions then react with the bicarbonate to form calcium carbonate. The overall reaction can be written as follows:

$$
\mathrm{Ca}^{2+}+2 \mathrm{HCO}_{3}^{-} \rightarrow \mathrm{CaCO}_{3(\mathrm{~s})}+\mathrm{CO}_{2(\mathrm{~g})}+\mathrm{H}_{2} \mathrm{O}
$$

The physical process involves ion clustering, nucleation, crystal growth, agglomeration, and deposition. Initially there is an incubation or induction period, where seed crystals form. Briefly, cationic and anionic species collide to produce ion pairs in solution. These pairs then go on to create microaggregates or unstable clusters, which become nucleation centres or seed crystals in a process known as homogenous nucleation. Alternatively, a liquid/surface boundary or the presence of particles can also promote crystal growth particularly if there are surface defects and areas of turbulent flow. This is known as heterogeneous nucleation [11]. As the micro-crystals continue to grow, they fuse to form adherent macro-crystals. Growth then continues via the further adsorption of scaling ions to eventually form a uniform coating with subsequent deposition covering the rough scaled surface [12].

Of significance to this study is that calcium carbonate precipitates in different polymorphic crystalline forms, which, albeit chemically identical, have different crystal lattice structures and macroand micro-structural properties. Three anhydrous crystalline polymorphs occur: vaterite, aragonite, and calcite and three hydrated phases, including amorphous calcium carbonate (ACC), monohydrate calcium carbonate (MCC; monohydrocalcite) and hexahydrate calcium carbonate (HCC; ikaite) [13]. The hydrated forms are unstable and most studies focus on the three anhydrous crystalline forms, of which calcite is the most stable, aragonite is metastable, and vaterite is the least stable form. Calcite and aragonite are the most common polymorphs (Fig.1).
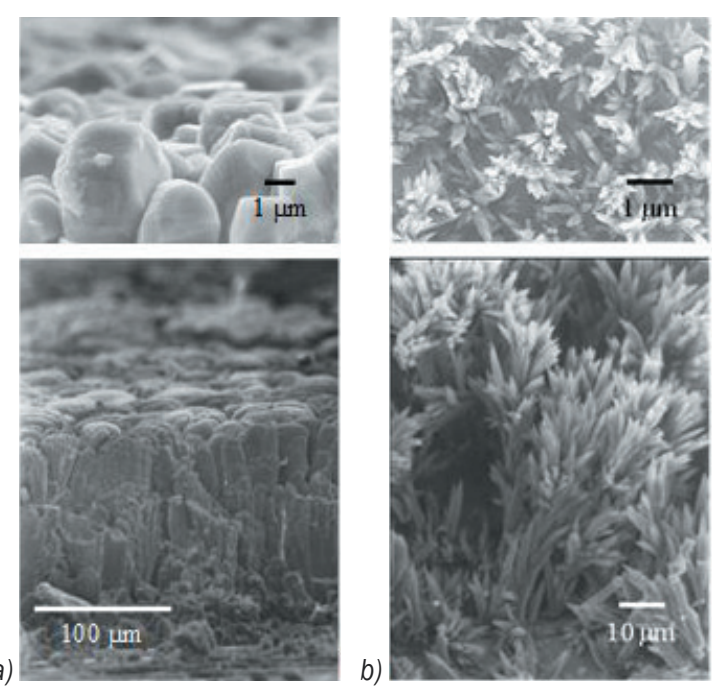

Fig. 1. Scanning electron micrographs of $\mathrm{CaCO}_{3}$ scale deposits showing the characteristic a) calcite ( $5 \mathrm{hrs}, T=18{ }^{\circ} \mathrm{C}, u=2 \mathrm{~m} / \mathrm{s}$, $p H=10.5, S=15.5)$ and $b)$ aragonite $\left(60 \mathrm{~min}, T=45^{\circ} \mathrm{C}\right.$, $u=0.41 \mathrm{~m} / \mathrm{s}, \mathrm{pH}=9.5, \mathrm{~S}=12$ ). Reprinted with permission from [14]. Copyright 1997 American Chemical Society

Factors affecting the rate of scale deposition and the type of polymorph include $\mathrm{pH}$, temperature, flow dynamics, surface properties, presence of other ions, and time. The higher the $\mathrm{pH}$, the greater is the tendency for scale to form. According to Andritsos and Karabelas [15], an increase in the $\mathrm{pH}$ from 8.8 to 
10 over a 2 hour period, will increase scale deposition from 2 to $12 \mathrm{mg} / \mathrm{cm}^{2}$. Aragonite content also increases with increasing $\mathrm{pH}$.

As stated, $\mathrm{CaCO}_{3}$ shows reverse solubility and, as water temperature increases, carbon dioxide is removed, which causes a shift in the equilibrium to the right. This results in an increase in $\mathrm{pH}$ and the precipitation of $\mathrm{CaCO}_{3}$. Additionally, Xia et al. [16] find that at lower temperatures, $\mathrm{CaCO}_{3}$ scale is denser and adheres more strongly to the substrate, while at higher temperatures it exhibits a characteristic dendritic crystal structure. This is explained by the fact that below $30{ }^{\circ} \mathrm{C}$, calcite is essentially the only polymorph present and is mainly in a prismatic form, while above $35{ }^{\circ} \mathrm{C}$, aragonite is stable and creates dendrite formations (Fig. 2).

a)

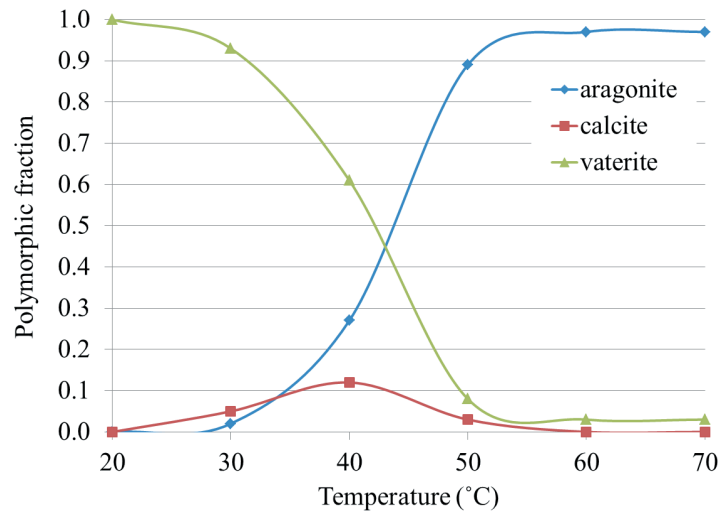

b)

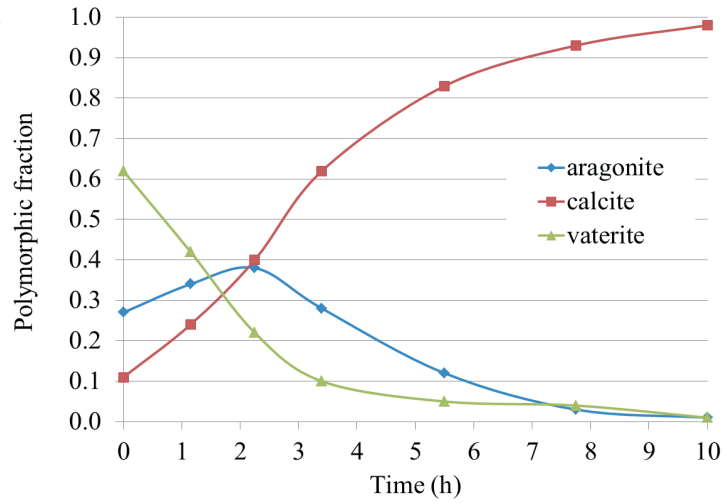

Fig. 2. The relative concentrations of calcite, aragonite and vaterite with a) temperature and b) time. Adapted from [17]

Vaterite can also be present at higher temperatures but it rapidly converts to calcite. The induction period increases with decreasing initial temperature because of the slower growth rate of $\mathrm{CaCO}_{3}$, which favours formation of calcite. During the post-induction period the rate of $\mathrm{CaCO}_{3}$ crystal growth is higher and favours the formation of aragonite [18] and [19].
Under low flow conditions a less dense scale will typically prevail, whereas higher flows result in a smoother surface. This is because the low density, poor coherence, and lower tenacity of aragonite mean it will be more easily removed. Scale properties are also influenced by the substrate surface in terms of size and crystal arrangement. For example, Malayeri et al. [3] find that highly alloyed austenitic stainless steel produces larger thicker harder and more adherent scale crystals. Time is also an important factor and with age the relative amount of calcite will increase.

It has long been known that the presence of other ions can affect scale formation from supersaturated solutions. Magnesium ions show the most pronounced affect [20] and [21]. Their presence not only delays and inhibits bulk precipitation and surface deposition processes, but also, to a different degree, favours the formation of the aragonite polymorph [20] and [21]. Low concentrations of magnesium ions in solution favour calcite formation, while aragonite is formed at high magnesium concentrations. It is the $\left(\mathrm{Mg}^{2+}\right):\left(\mathrm{Ca}^{2+}\right)$ ratio and the initial ionic product of carbonate in solution that controls the time of nucleation and the mineralogy of the precipitate when $\mathrm{Mg}^{2+}$ ions are present [20]. The exact mechanism is not fully understood but it is thought that $\mathrm{Mg}^{2+}$ ions poison calcite crystal growth by becoming incorporated into the $\mathrm{CaCO}_{3}$ lattice at $\mathrm{Ca}$ sites thus affecting its morphology and growth [21] and [22].

\section{ULTRASONIC SCALE REMOVAL}

Ultrasonic cleaning is a technology that uses high frequency sound waves and combines the phenomenon of cavitation, which dislodges contaminants, and agitation (micro-streaming), which accelerates the dissolution of contaminants by supplying fresh solution to the surface being cleaned. Cavitation describes the life-cycle of a transient cavity or bubble from formation via inception and nucleation, its expansion, and its eventual implosion. The result is extremely high pressure shock-waves (Table 2) and temperatures (approx. 5,000 K). Its observable effect, when near a solid boundary, is material damage known as cavitation erosion. Acoustically driven cavitation is the most important source of the cavitation effect for practical purposes, although it is also possible to utilise hydrodynamic cavitation in scale prevention [23]. Cavitation occurs as an acoustic wave (20 to $100 \mathrm{kHz}$ ) passes through a fluid. This then creates oscillating pressure with resultant phases of compression and rarefaction. During rarefaction, molecules are increasingly pulled 
apart, eventually forming a cavity or void [24]. Fig. 3 shows how a bubble grows and collapses in an ultrasonic field. In reality, pre-existing nucleation sites require less energy to develop into bubbles. These sites are typically micro-heterogeneities, such as tiny gas bubbles, gas bubbles trapped in pockets and in crevices, trace impurities, and solid particles [25]. In most situations ample nuclei exist for bubble formation [26]. Two distinct types of bubble oscillations exist. The first are "stable" bubbles that oscillate for many periods of the sound field, while the second are "transient" (inertial) unstable bubbles that exist for less than a single compression half-cycle and increase in size 2 to 3 times their resonant size before imploding [27]. This transformation of a low energy density sound wave into a high energy density one means that a collapsing bubble will concentrate the energy into very small volumes producing extreme pressures (shock waves), temperatures, and even light in a process known as sonoluminescence [26]. Fig. 3 gives an overview of ultrasonic cavitation.

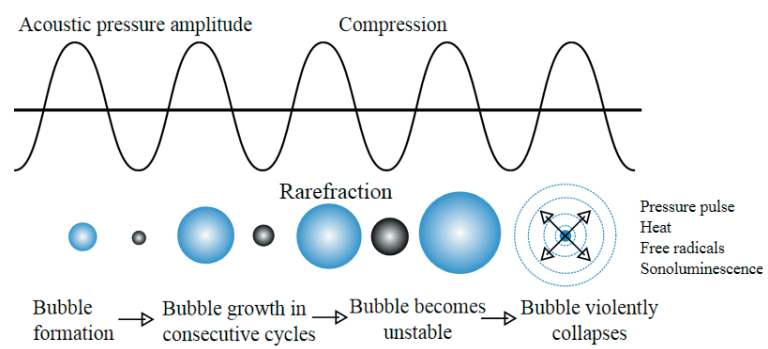

Fig. 3. A generalised view of bubble dynamics in an ultrasonic field

In terms of pressure as a damage mechanism, the forces impacting a surface are a result of spherical bubble collapse, impact of micro-jets [28], splash effect following the impact of a jet [29] and the combined effect of multi-bubble systems known as "clouds" [30]. The interaction of these shock waves subjects a material to repeat localized loading. The actual mechanisms producing shock waves of sufficient energy to cause material damage are a continual point of debate. Table 2 gives some examples of cavitation pressure loadings reported in the literature. Comparing these values is, however, difficult because some are estimates while others are measured using different methods and different ways of producing the cavitation phenomenon. In addition, the extreme pressure produced in the centre of the bubble decreases dramatically over very short distances. Spherical bubble collapse was the focus of initial investigations, but this is now known to be only a part of a more complex phenomenoa, since not all bubbles collapse spherically and their effect cannot be considered in isolation.

Bubbles that interact with a surface (rigid boundary) and with other bubbles will collapse in a non-spherical or asymmetrical manner, which in turn results in a re-entrant jet that is capable of delivering a directional and much higher local impact. Many authors believe that the shock waves produced by single bubble collapse and jet formation cannot account for much of the observed macroscopic damage and they focus on the combined effect of multiple bubble systems (clouds) and the so-called "splashing effect" as a major damage mechanism, [29] to [33].

Table 2. Examples of cavitation load pressure

\begin{tabular}{|c|c|c|c|}
\hline Source & Pressure [GPa] & $\begin{array}{l}\text { Bubble } \\
\text { collapse }\end{array}$ & $\begin{array}{l}\text { Cavitation } \\
\text { source }\end{array}$ \\
\hline [34] & 10 & single bubble & spark induced \\
\hline [35] & 0.2 & micro-jet & ultrasound \\
\hline [36] & $\begin{array}{l}4(200 \mu \mathrm{m}) \\
4.8 \text { to } 8.1(200 \mu \mathrm{m})\end{array}$ & & $\begin{array}{l}\text { hydrodynamic, } \\
\text { vibratory }\end{array}$ \\
\hline [37] & 0.1 & single bubble & \\
\hline [37] & 0.15 & micro-jet & \\
\hline [38] & 2.5 & & $\begin{array}{l}\text { simulated and } \\
\text { hydrodynamic }\end{array}$ \\
\hline [39] & 1.7 & single bubble & hydrodynamic \\
\hline [40] & 1 & & \\
\hline [41] & $\begin{array}{l}1.85 \text { to } 2.24(200 \mu \mathrm{m}) \\
285 \text { to } 336(10 \mu \mathrm{m})\end{array}$ & & hydrodynamic \\
\hline [42] & $\begin{array}{l}4.3(70 \mu \mathrm{m}) \\
720(4 \mu \mathrm{m})\end{array}$ & & $\begin{array}{l}\text { hydrodynamic, } \\
\text { vibratory }\end{array}$ \\
\hline [43] & 0.55 & single bubble & ultrasound \\
\hline [44] & 0.1 & multi -bubble & ultrasound \\
\hline [45] & $\begin{array}{l}4 \text { to } 16 \mathrm{MPa} \\
\text { (10 mm from bubble) }\end{array}$ & & ultrasound \\
\hline [46] & 4 to 6 & & \\
\hline [47] & $\begin{array}{l}8 \text { (at bubble wall) } \\
1.3 \pm 0.3 \\
(68 \mu \mathrm{m} \text { from bubble })\end{array}$ & single bubble & ultrasound \\
\hline [48] & 7 & single bubble & hydrodynamic \\
\hline [49] & 1.5 & $\begin{array}{l}\text { hemi-spherical } \\
\text { cloud ( } 760 \\
\mu \mathrm{m})\end{array}$ & ultrasound \\
\hline
\end{tabular}

Developing an understanding of cloud phenomena is difficult because whereas individually collapsing bubbles can be observed experimentally, shock waves arising from a concerted collapse of bubbles in a cloud system involve more complex dynamics [50] and [51]. In a bubble cloud, the entire bubble population dominates the cavitation effect and the collapse of the cloud creates a shock wave that radiates out into the fluid, the magnitude of which is attenuated as it travels 
toward a solid surface. Williams et al. [52] suggest that jet formation may be enhanced by bubble-shockwave interaction. Brujan et al. [47] believe that collapsing clouds are potentially the most destructive form of cavitation as they produce short duration pressure pulses of large magnitude (1.5 GPa). Van Terwisga et al. [53] argue that the acoustic power released from a synchronized bubble cloud collapse is greater than that released via a micro jet. These shock waves are of interest in those cases where bubbles collapse at a distance from a boundary so that no jets form [53] and [54]. More recently, Brujan et al. [55] investigated secondary shock waves, which are a consequence of the free collapse of a bubble within the cloud by the ambient pressure in the fluid. In the second case, it is a consequence of the interaction of the cloud-collapseinduced shock wave with micro-bubbles situated close to the collapse site of the cloud. The latter can be very powerful, resulting in a secondary shock wave emission with a maximum amplitude of about $0.5 \mathrm{GPa}$. Despite this, Brujan [56] finds that, whereas small jet velocities do not have the potential to produce erosion of metals, they can play an important role in the fragmentation of brittle materials, since the yield strength is much lower than for ductile materials. Also of interest is a study by Barrow et al. [57] using atomic force microscopy, where the authors suggest that rapidly growing cavities have the potential to damage adjacent structures by the development of tension rather than by the evolution of a (positive) pressure shock. This type of damage together with micro-streaming could have a significant effect on the removal of the poorly adhering dendritic crystal structure, i.e. aragonite.

\section{INFLUENCES OF MATERIAL PROPERTIES ON CAVITATION EROSION}

From the published studies it can be seen that cavitation erosion is a function of material properties, including macro-properties, such as: tensile strength, strain energy, resilience, ductility, hardness, fatigue resistance and its microstructure [58]. To date, no overall single or combination of material properties can adequately predict cavitation erosion [59] and [60]. What is certain is that cavitation erosion is a time dependent phenomenon classically represented by an S-shaped erosion curve (Fig. 4) of material loss or rate of material loss against time [61]. The four distinct stages identifiable are the following: an incubation period, an acceleration period, a deceleration period, and finally a period of steady state erosion. The
S-curve is a generalisation and the actual shape is specific to a material's properties.

The incubation period represents the accumulation of plastic deformation and internal stresses under the surface that precedes significant material loss [62] and [63]. It is related to the accumulation of fatigue damage but many other factors including, for example, grain size, hardness, and plasticity are also relevant. In ductile materials, cavitation shock waves impacting the surface will cause work hardening. Eventually, micro-cracks appear around grain boundaries and surface heterogeneities and begin to propagate outwards. In metals, these include notches, tears, undercuts, welding defects, inclusions or at heterogeneous areas of the material such as at the directionality of metal flow and decarburized sections [64]. Eventually the material will no longer be able to withstand such shocks and material will break loose [65] and [66]. This represents the transition from the incubation to the acceleration period. Initially the rate of material loss is exponential but becomes linear as the volume loss rate reaches a maximal value.

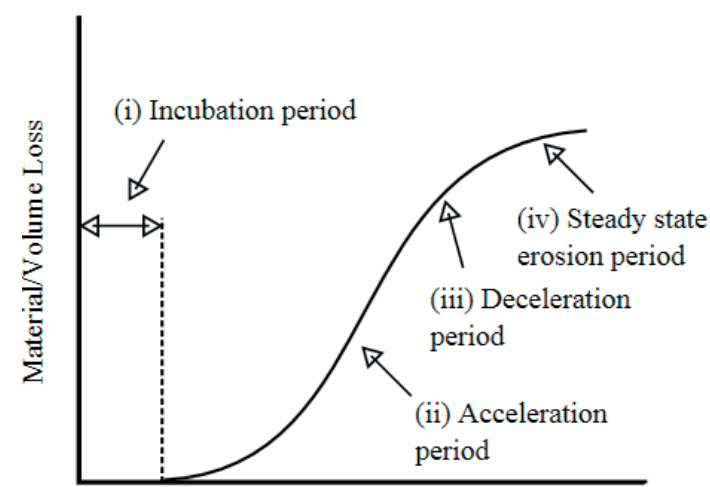

a)

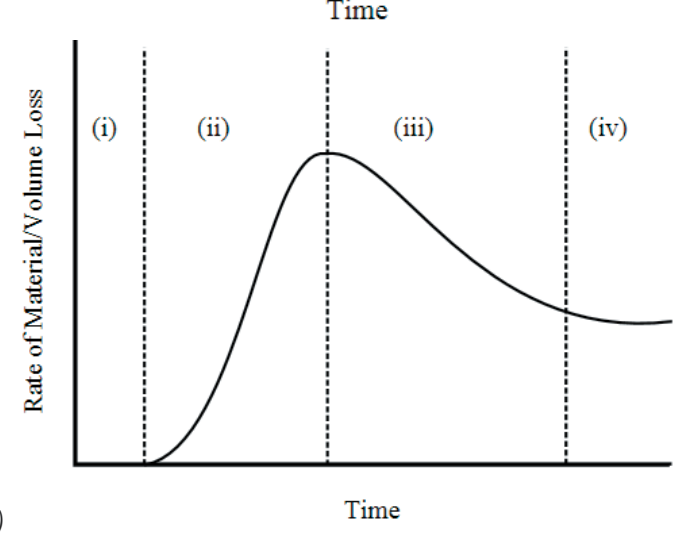

Fig. 4. General cavitation erosion s-curve of material loss with time (a) showing four distinct stages (b). The rate that material is lost is initially slow but then steadily increases up to a point of maximum damage after which it (the damage rate) decreases until a steady-state condition is achieved. Adapted from [67] 
A lessening in the rate of this damage typifies the deceleration period. The volume loss rate decreases and removal of new material uncovers major areas with no accumulated internal stresses. Eventually, the erosion reaches a steady state with an almost constant volume loss rate since the surface, that is already strongly fractured, behaves as a protective cushion.

In brittle materials, zero or only a limited amount of plastic deformation occurs. Instead, micro-fractures will appear at the onset and cracks will rapidly propagate without increasing the overall applied stress. The erosion curve can still show the four characteristic stages of cavitation erosion since the incubation period reflects the accumulation of microcracks up to a point where material will break free. In addition, when erosion begins it becomes much more intensive than in ductile materials. The slope of the acceleration part of the cavitation erosion curve will be much steeper so that, in the end, the cumulated mass loss will be greater than in ductile materials given the same exposure time and cavitation intensity.

Fatjo et al. [68] find that for silicon nitride and zirconia pseudoplastic deformation pits are visible, but, unlike the work hardening seen in metals, there is a softening effect on the surface and the observable pits are linked to crack creation. The authors also describe how in ceramics these erosion pits have micro-cracks extension at the boundaries and cracking is mainly intergranular, although some cracks are visible within large or elongated grains. According to Karunamurthy et al. [69], material is removed as cracking eventually leads to dislodging of partial grains, grains, and eventually whole grain clusters. The transition from the incubation period to the acceleration period will occur when erosion of the entire surface is at a depth approximately equal to the average grain size [70]. $\mathrm{Lu}$ et al. [71] state that micro-structures including grain size, phases at grain boundaries, cavities or pores, and defects, such as cracks, inclusions, single agglomerates of large grains, and scratches from machining, promote fracture between grains. These structures are important in controlling the cavitation erosion behaviour of ceramic materials. Grain size is also important; increasing grain size leads to a greater erosion rate and vice versa [63].

Cavitation erosion is a natural process but only a few studies exist that investigate the cavitation of carbonate rocks. Carbonate rocks are made up of calcite crystals and hence provide valuable information about how cavitation can affect hard scale deposits. For instance, Momber, [72] having studied the cavitation erosion of limestone and marble using a flow cavitation chamber, finds that the most important parameters influencing cavitation erosion are exposure time, cavitation intensity, and materials properties. Grabco et al. [73] find that, in addition to mineral composition and mechanical properties like hardness, strength, fracture, and stability, microstructure is an important factor in the erosion resistance of brittle minerals. Calcite is unusual in that the presence of cleavage plane slip bands allows a limited amount of plastic deformation, while aragonite, having a single plane cleavage, does not. Generally, in such material, plastic deformation is relatively small and the formation of micro-cracks is the most important dissipation mechanism of inelastic deformation and brittle failure. This is enhanced by the presence of structural homogeneities like pores and interfaces, and pre-existing flaws are important sites where damage initiates while additional energy is absorbed due to crack surface friction (frictional resistance to sliding), crack bridging, and micro-crack formation [74].

There exist two possible mechanisms of brittle fracture: transcrystalline and intercrystalline cleavage. Lubarda et al. [75] find that, in most cases, it is inelastic deformation that occurs in rocks. As with ceramics, micro-cracks begin and propagate at the surface of pores and grain boundaries, and most evidence is for the damage being intercrystalline rather than transcrystalline fracture. In the case of limestone and marble, Momber [72] observes two erosion zones of high and low intensity in his samples of carbonaceous rocks. In the high intensity zone there is considerable erosion, while in the low intensity zone there are only a few single erosion events, which is a result of the flow conditions in the cavitation chamber. For marble and limestone, the transition or threshold time (critical exposure time) from there being just a few singular erosion events to producing a large cavity (damage) was 30 and $90 \mathrm{~s}$, respectively. Low intensity cavitation of the limestone exposed coarse grain conglomerates 800-1000 $\mu \mathrm{m}$ in diameter. At higher intensity, individual grains $100 \mu \mathrm{m}$ in diameter (approximately two times cleavage spacing of the calcite crystals) were exposed and removed. For marble, the author observes exposed individual calcite crystals $(800$ $\mu \mathrm{m})$ at the surface and transcrystalline cleavage (200 $\mu \mathrm{m}$ cleavage planes) in the calcite minerals, indicating that marble is eroded in a two-step mode. The author proposes that fracture toughness and, secondly, structural homogeneity (pre-existing flaws) are good indicators of cavitation erosion, as erosion mainly occurs in an intergranular or intercrystalline mode and erosion resistance decreases with grain size. Wagterveld et al. [19] investigating cavitation erosion of suspended calcite crystals find that crystal breakage 
can only occur if the energy input is higher than the energy required for maximum elastic deformation.

For transcystralline cleavage, the strength of the shock wave pressure pulses would have to be significant given the hardness of calcite (Vickers hardness of 1.2 to $1.5 \mathrm{GPa}$ ), with aragonite being slightly harder [76] and [77]. This is feasible given the strength of cavitation pressure pulses $(>1.5 \mathrm{GPa})$ reported in the literature. There is evidence suggesting that the strength of the crystal bonds may be higher than actually necessary to cause transcrystalline crystal cleavage. However, Wagterveld et al. [19], observing suspended calcite crystals, find that less energy is required to break off small fragments of corners by attrition compared to large fragments as total crystal breakage. The authors also find a discrepancy between theoretical surface fracture energies, defined by material bond strength, and their experimentally observed surface fracture energies, which they relate to so-called "Griffith cracks". These exist as microscopic flaws in the crystal grains. The numbers of these cracks are known to increase with volume, causing large grains to fracture more easily. This may also explain why cavitation erosion resistance increases with decreasing crystal grain size. Fatjo et al. [78] observe in ceramic materials that, while cracking is mainly intergranular, some cracks are also visible within larger or elongated grains. Wagterveld et al. [19] find no evidence of re-entrant jet impacts.

Amongst those studies that look at removing scale using cavitation erosion specifically, most are involved with the precipitation of scale in the bulk fluid rather than how cavitation actually affects surface deposits. In addition, the effects of ultrasound on preventing mineral scale from forming are not fully understood, despite several studies that have looked directly at preventing scale deposits [79] to [82]. In most cases they do not directly discuss the effects of cavitation erosion.

Dalas [79] was one of the first to apply ultrasound to preventing scale and reports that ultrasound retards $\mathrm{CaCO}_{3}$ precipitation (reduction in scale by 62 to $76 \%$ ) but has no effect on morphology. According to Li et al. [81], during cavitation, scale is "shattered and abscised". The authors find that temperature is an important factor when removing scale with ultrasound, e.g. $40{ }^{\circ} \mathrm{C}$ is preferable for preventing scale, whereas $50{ }^{\circ} \mathrm{C}$ is better for removing scale. They also conclude that a stronger acoustic intensity is better for removing scale deposits and vice versa a lower acoustic intensity is better for mitigating scale precipitation. Similarly, Feng et al. [83] also find that distance to the transducer is a factor.

Nishida [84], performing a sonochemical study, describes how ultrasonic irradiation and not cavitation increases the precipitation rate of $\mathrm{CaCO}_{3}$ by enhancing nucleation. They also find that physical mixing by macro-streaming, rather than either a chemical effect or micro-streaming, is responsible for the observed increase in the rate of precipitation. Mihai et al. [85] also observed that ultrasound increases the precipitation rate (nucleation) by $40 \%$, but reduces "association" (sic), i.e. crystal growth and agglomeration of the precipitated particles. He et al. [86] make similar observations but suggest that the reduction in average measured particle size is due to rapid nucleation resulting from the supersaturation of $\mathrm{Ca}^{2+}$ around the cavitating bubbles. Santos et al. [87] have investigated ultrasound as a means to break up the particle size of a $\mathrm{CaCO}_{3}$ powder as a method for increasing mineral carbonation. The authors found a significant reduction in particle size. More recently, Price et al. [88], investigating the composition of $\mathrm{CaCO}_{3}$ polymorphs precipitated using ultrasound, did not observe the retardation effect reported by Dalas [79] and state that this contradiction is a result of different reaction conditions. Price et al. [88] also find that the yield of $\mathrm{CaCO}_{3}$ increases in the presence of an ultrasonic field until a maximum is reached, which is consistent with Nishida [84].

There is also the potential for cavitation to break up agglomerates. Marković et al. [89] investigated acoustic cavitation and fracture de-agglomeration of barium titanate powder and report that cavitation pressure must be larger than the cohesive strength by which primary particles are bound together. The authors find little evidence of changes in crystal structure, but were able to break up agglomerates and found that damage is maximised at crystal boundaries. Price et al. [88], however, unlike Dalas [79], did find that under specific reaction conditions different polymorphs of calcite are formed during irradiation with ultrasound, but that ultrasound has only a small effect on the polymorphs produced. The most important factor is initial concentration (supersaturation). This was not the case for Kojima et al. [90] who, by applying larger amplitudes, could promote the formation of the less stable vaterite phase and who suggest that morphological control of $\mathrm{CaCO}_{3}$ is possible. Mateescu et al. [91] find that an ultrasonic field accelerates the formation of stable phases (calcite) from metastable ones (aragonite). Santos et al. [92] successfully use ultrasound combined with the addition of $\mathrm{Mg}^{2+}$ to promote aragonite synthesis 
and suggest it as a potential method for industrial production of pure aragonite powder.

Since, in many cases, scale forms a coherent layer, information about damage from repeated shock impact can be gained from studies investigating surface treatments and coatings as strategies for improving cavitation erosion resistance. Such studies, besides investigating polymers, composites, and fillers, also investigate hard brittle coatings made of ceramics [93]. On their own, these coatings are resilient to cavitation but, despite some initial success, fail over time [94]. Buravova and Gordopolov [95] observe that pressure loading on the outer surface, albeit of insufficient strength to fracture the surface, i.e. below the yield stress, can still cause damage. Failure mechanisms include debonding, delamination, and spallation [96] to [99]. Damage occurs when a reflected shock wave is generated when the incident shock hits the material boundary. The interaction and focusing of the incident and reflected shock waves cause subsurface cracks to form parallel to the interface. Delamination then occurs as these cracks extend along a plane parallel to the film/substrate interface, while spalling occurs when the subsequent propagation travels up through the film to the surface. Spalling is a common damage mechanism seen in hard coatings [100]. Ledrappier et al. [101] observe that such damage mechanisms depend on impact parameters and coating characteristics. Additional factors include residual stresses, substrate properties and substrate coating adherence issues, porosity and interfacial defects, and other imperfections [102]. Such sites (imperfections) can also act as nucleation sites for cavitation, thus further accelerating material removal. Loh et al. [103] find that spalling only occurs at defective regions of a coating, while nondefective regions are apparently immune to spalling.

Acoustic pressure also differs according to material properties that affect the speed of sound waves as they travel through different materials. This in itself can lead to a damaging shearing force [104]. Such a force acting on a scale deposit is therefore another damage mechanism causing material (scale) to become loose and break free.

Cavitation erosion creates free particles in solution, making particulate abrasion a possibility since cavitation is accompanied by acoustic streaming [105]. Krella et al. [97] provide evidence of possible abrasion/erosion that results from collisions of the hard coating micro-particles torn off during cavitation, while Chen et al. [106] report enhanced cavitation erosion in the presence of particles. Zeiger et al. [107], investigating the molecular crystals (aspirin), rule out particle-particle interaction as a viable damage mechanism.

Removal of material could result from cavitation affecting changes in the chemical equilibrium that exist close to a surface deposit. Stephanis et al. [108] find that for gypsum, another common scale forming mineral, dissolution from the solid occurs since solvent is being continuously renewed at the point of jet impact due to asymmetrical bubble collapse. Vinten'ko and Gumnitskii [109], investigating the dissolution of the mineral Langbeinite $\left(\mathrm{K}_{2} \mathrm{Mg}_{2}\left(\mathrm{SO}_{4}\right)_{3}\right)$, draw a similar conclusion and also suggest that cavitation enhances the dissolution of solids. In the case of $\mathrm{CaCO}_{3}$ this would benefit from further investigation.

Another minor removal mechanism of interest is possibility the direct volatilisation of $\mathrm{CaCO}_{3}$ to $\mathrm{CaO}$ and $\mathrm{CO}_{2}$. Impact simulations of carbonaceous material suggest that approximately $10 \mathrm{GPa}$ is the minimum shock pressure required for partial release of $\mathrm{CO}_{2}$ from $\mathrm{CaCO}_{3}$, while 60 to $70 \mathrm{GPa}$ is necessary for complete conversion. Recent studies continue to show lower shock pressure required for incipient devolatilization of calcite, e.g. $<24.9 \pm 2.6 \mathrm{GPa}$ [110] and $18 \mathrm{GPa}$ [111], which is significantly lower than reported in previous experimental studies. Grady [112] referenced in [113] states that at a "Static high pressure, high temperature experiments up to 3.5 $\mathrm{GPa}$ on calcite show that below $4 \mathrm{MPa}$ it decomposes into solid $\mathrm{CaO}$ and gaseous $\mathrm{CO}_{2}$ without melting". Pressure pulses from cavitation, especially when bubbles collapse close to a surface, may be sufficient to cause partial devolatilization since pressures of 10 $\mathrm{GPa}$ are potentially feasible at liquid-solid interfaces [114]. The presence of a back reaction resulting in the re-precipitation of secondary carbonates may also greatly diminish this effect. Overall, too little is known about the extent of devoltaliszation of $\mathrm{CaCO}_{3}$ under cavitating conditions.

\section{CONCLUSIONS}

Our objective in writing this paper was to review the major aspects of the possible cavitation erosion mechanisms affecting tenacious $\mathrm{CaCO}_{3}$ mineral scale as part of a larger study examining the influence of cavitation on different mineral scale coated metal surfaces. Our eventual aim is to formulate a phenomenological model of cavitation erosion, which will link parameters of cavitation intensiveness with damage of the mineral scale surface. This literature study shows how scale formation and cavitation erosion are complex phenomena dependent on many factors. The density, hardness, and tenacity of the 
scale will depend on its depositional environment. In the case of $\mathrm{CaCO}_{3}$, this will affect the material and surface properties of the resultant scale layer. Of the different mechanism of cavitation, bubble cloud collapse and the splashing effect following jet formation are considered to be the most important. Cavitation erosion suggests that brittle material fracture occurs with only a limited amount of plastic deformation and that the formation of micro-cracks is the most important erosion mechanism, enhanced by the presence of structural homogeneities. A better understanding of the damage mechanism of cavitation will be useful not only for those looking at improving the efficiency of ultrasonic removal of tenacious mineral scale deposits, but will also prove useful in the field of sonochemistry, medicine (shock wave lithotripsy), and those studying the natural cavitation processes of carbonate materials.

\section{REFERENCES}

[1] DOE (2011). EnergySavers: Tips on Saving Money \& Energy at Home, US Department of Energy, Office of Energy Efficiency and Renewable Energy, p. 1-44.

[2] Müller-Steinhagen, H., Malayeri, M.R., Watkinson, P. (2005). Fouling of heat exchangers -new approaches to solve old problem. Heat Transfer Engineering, vol. 26, no. 1, p. 1-4, DOI:10.1080/01457630590959250.

[3] Malayeri, M.R., Al-Janabi, A., Müller-Steinhagen, H. (2009). Application of nano-modified surfaces for fouling mitigation. International Journal of Energy Research, vol. 33, no. 13, p. 1101-1113, DOI:10.1002/ er.1599.

[4] MarketsandMarkets. (2012). Scale Inhibitors Market (2011-2016), from http://www.marketsandmarkets. com/, accessed at: 2012-02-01.

[5] Hasson, D., Shemer, H., Sher, A. (2011). State of the art of friendly "green" scale control inhibitors: a review article. Industrial \& Engineering Chemistry Research, vol. 50, no. 12, p. 7601-7607, DOI:10.1021/ ie $200370 \mathrm{v}$.

[6] Hansen, J.T., Saxon G.E. (2004). Improving condenser efficiency with innovative scale removal system technology. ASME 2004 Conference Proceedings, p. 19-23, DOI:10.1115/POWER2004-52020.

[7] Širok, B., Dular, M., Stoffel, B. (2006). Cavitation. i2, Publishing, Ljubljana.

[8] Brennen, C.E. (1995). Cavitation and Bubble Dynamics. Oxford University Press, New York, Oxford.

[9] MacAdam, J., Parsons, S.A. (2004). Calcium carbonate scale formation and control. Reviews in Environmental Science and Biotechnology, vol. 3, no. 2, p. 159-169, DOI:10.1007/s11157-004-3849-1.

[10] Karabelas, A.J. (2002). Scale formation in tubular heat exchangers - research priorities. International
Journal of Thermal Sciences, vol. 41, no. 7, p. 682692, DOI:10.1016/S1290-0729(02)01363-7.

[11] Crabtree, M., Eslinger, D., Fletcher, P., Miller, M., Johnson, A., King, G. (1999). Fighting scale-removal and prevention. Oilfield Review, vol. 11, no. 3, p. 3045.

[12] Duggirala, P.Y. (2005). Formation of calcium carbonate scale and control strategies in continuous digesters. CD del II Coloquio Internacional sobre Celulosa de Eucalipto, Concepcion, Chile, p. 1-34.

[13] Elfil, H., Roques, H. (2001). Role of hydrate phases of calcium carbonate on the scaling phenomenon. Desalination, vol. 137 , no. 1-3, p. 177-186, DOI:10.1016/S0011-9164(01)00216-8.

[14] Andritsos, N., Karabelas, A.J., Koutsoukos, P.G. (1997). Morphology and structure of $\mathrm{CaCO}_{3}$ scale layers formed under isothermal flow conditions. Langmuir, vol. 13, p. 2873-2879, DOI:10.1021/ la960960s.

[15] Andritsos, N., Karabelas, A.J. (1999). The influence of particulates on $\mathrm{CaCO} 3$ scale formation. Journal of Heat Transfer-Transactions of the ASME, vol. 121, no. 1, p. 225-227, DOI:10.1115/1.2825951.

[16] Xia, M.Z., Lei, W., Dai, L.H., Chu, Y. T., Wang, F.Y. (2010). Study of the mechanism of phosphonate scale inhibitors against Calcium carbonate scale. Acta Chimica Sinica, vol. 68, no. 2, p. 143-148.

[17] Carteret, C., Dandeu, A., Moussaoui, S., Muhr, H., Humbert, B., Plasari, E. (2009). Polymorphism studied by lattice phonon raman spectroscopy and statistical mixture analysis method. Application to calcium carbonate polymorphs during batch crystallization. Crystal Growth \& Design, vol. 9, no. 2, p. 807-812, DOI:10.1021/cg800368u.

[18] Yang, Q.F., Liu, Y.Q., Gu, A.Z., Ding, J., Shen, Z.Q. (2002). Investigation of induction period and morphology of $\mathrm{CaCO}_{3}$ fouling on heated surface. Chemical Engineering Science, vol. 57, no. 6, p. 921931, DOI:10.1016/S0009-2509(02)00007-6.

[19] Wagterveld, R.M., Boels, L., Mayer, M.J., Witkamp, G.J. (2011). Visualization of acoustic cavitation effects on suspended calcite crystals. Ultrasonics Sonochemistry, vol. 18 , no. 1, p. 216-225, DOI:10.1016/j.ultsonch.2010.05.006.

[20] Rushdi, A., Pytkowicz, R., Suess, E., Chen, C.T., (1992). The effects of magnesium-to-calcium ratios in artificial seawater, at different ionic products, upon the induction time, and the mineralogy of calcium carbonate: a laboratory study. Geologische Rundschau, vol. 81, no. 2, p. 571-578, DOI:10.1007/ BF01828616.

[21] Chen, T., Neville, A., Yuan, M. (2006). Influence of $\mathrm{Mg}^{2+}$ on $\mathrm{CaCO}_{3}$ formation-bulk precipitation and surface deposition. Chemical Engineering Science, vol. 61, no. 16, p. 5318-5327, DOI:10.1016/j. ces.2006.04.007.

[22] Stashans, A., Chamba, G. (2011). A new insight on the role of $\mathrm{Mg}$ in calcite. International Journal of 
Quantum Chemistry, vol. 111, no. 10, p 2436-2443, DOI:10.1002/qua.22538.

[23] Gaines, W.A., Kim, B.R., Drews, A.R., Bailey, C., Loch, T. (2007). Controlling cooling water quality by hydrodynamic cavitation. Proceedings of the Water Environment Federation Conference, vol. 7, p. 538545, DOI:10.2175/193864707787781656.

[24] Leighton, T.G. (1998). Fundamentals of underwater acoustics and ultrasound. Fahy, F.J., Walker, J.G. (eds.). Noise and Vibration, E\&F Spon, London, p. 373-444.

[25] Mørch, K.A. (2007). Reflections on cavitation nuclei in water. Physics of Fluids, vol. 19, no. 7, p. 1-7, DOI:10.1063/1.2747210.

[26] Davydov, M.N., Kedrinskii, V.K. (2003). Mathematical simulation of bubbly cluster and spall formation in a liquid at dynamic loading. $5^{\text {th }}$ International Symposium on Cavitation, Osaka.

[27] Riesz, P., Kondo, T. (1992). Free radical formation induced by ultrasound and its biological implications. Free Radical Biolology and Medicine, vol. 13, no. 3, p. 247-270, DOI:10.1016/0891-5849(92)90021-8.

[28] Benjamin, T.B., Ellis, A.T. (1966). The collapse of cavitation bubbles and the pressures thereby produced against solid boundaries. Philosophical Transactions of the Royal Society of London. Series A, Mathematical and Physical Sciences, vol. 260, no. 1110, p. 221-240, DOI:10.1098/rsta.1966.0046.

[29] Tong, R.P., Schiffers, W.P., Shaw, S.J., Blake, J.R., Emmoy, D.C. (1999). The role of 'splashing' in the collapse of a laser-generated cavity near a rigid boundary. Journal of Fluid Mechanics, vol. 380, p. 339-361, DOI:10.1017/S0022112098003589.

[30] Dular, M., Bachert, B., Stoffel, B., Širok, B. (2004). Relationship between cavitation structures and cavitation damage. Wear. vol. 257, no. 11, p. 11761184, DOI:10.1016/j.wear.2004.08.004.

[31] Hansson, I., Mørch, K.A. (1980). The dynamics of cavity clusters in ultrasonic (vibratory) cavitation erosion. Journal of Applied Physics, vol. 51, no. 9, p. 4651-4658, DOI: 10.1063/1.328335.

[32] Dular, M., Stoffel, B., Širok, B. (2006). Development of a cavitation erosion model. Wear, vol. 26, no. 5-6, p. 642-655, DOI:10.1016/j.wear.2006.01.020.

[33] Dular, M., Osterman, A. (2008). Pit clustering in cavitation erosion. Wear, vol. 265, no. 5-6, p. 811820, DOI:10.1016/j.wear.2008.01.005.

[34] Jones, I.R., Edwards D.H. (1960). An experimental study of the forces generated by the collapse of transient cavities in water. Journal of Fluid Mechanics, vol. 7, no. 4, p. 596-609, DOI:10.1017/ S0022112060000311.

[35] Crum, L.A. (1979). Tensile strength of water. Nature, vol. 278, no. 5700, p. 148-149, DOI:10.1038/278148a0.

[36] Kirejczyk, J. (1979). The energy flux of cavitating flow. Proceedings of $6^{\text {th }}$ International Conference on Fluid Machinery. Budapest Scientific Society of Mechanical Engineers, Budapest, p. 555.

[37] Fujikawa, S., Akamatsu, T. (1980). Effects of the nonequilibrium condensation of vapour on the pressure wave produced by the collapse of a bubble in a liquid. Journal of Fluid Mechanics, vol. 97, no. 3, p. 481512, DOI:10.1017/S0022112080002662.

[38] Patella, R.F., Reboud, J.L. (1998). A new approach to evaluate the cavitation erosion power. Journal of Fluids Engineering, vol. 120, no. 2, p. 335-344, DOI:10.1115/1.2820653.

[39] De, M.K., Hammitt, F.G. (1982). Instrument system for monitoring cavitation noise. Journal of Physics E: Scientific Instruments, vol. 15, no. 7, p. 745, DOI:10.1088/0022-3735/15/7/012.

[40] Takayama, K., Esashi, H., Sanada, N. (1983) Propagation and focusing of spherical shock waves produced by underwater microexplosions. Shock tubes and waves, Archer, R.D., Milton, B.E. (eds.), Sydney Shock Tube Symposium, Sydney, p. 553-562.

[41] Momma, T., Lichtarowicz, A. (1995). A study of pressures and erosion produced by collapsing cavitation. Wear, vol. 186-187, no. 2, p. 425-436, DOI:10.1016/0043-1648(95)07144-X

[42] Okada, T., Iwai, Y., Hattori, S., Tanimura, N. (1995). Relation between impact load and the damage produced by cavitation bubble collapse. Wear, vol. 184, no. 2, p. 231-239 DOI:10.1016/00431648(94)06581-0.

[43] Holzfuss, J., Ruggeberg, M., Billo, A. (1998). Shock Wave Emissions of a Sonoluminescing Bubble. eprint arXiv:chao-dyn/9811022:11022, PhysRevLett.81.5434.

[44] Suslick, K.S., McNamara III, W.B., Didenko, Y. (1999). Hot spot conditions during multi-bubble cavitation. Sonochemistry and Sonoluminescence. Crum, L.A., Mason, T.J., Reisse, J., Suslick, K.S. (eds.) Kluwer Publishers, Dordrecht, p. 191-204.

[45] Cleveland, R.O., Sapozhnikov, O.A., Bailey, M.R., Crum, L.A. (2000). A dual passive cavitation detector for localized detection of lithotripsy-induced cavitation in vitro. The Journal of the Acoustical Society of America, vol. 107, no. 3, p. 1758, DOI:10.1121/1.428572.

[46] Pecha, R., Gompf, B. (2000). Microimplosions: Cavitation collapse and shock wave emission on a nanosecond time scale. Physical Review Letters, vol. 84, no. 6, p. 1328-1330, DOI:10.1103/ PhysRevLett.84.1328.

[47] Brujan, E.A., Ikeda, T., Matsumoto, Y. (2008). On the pressure of cavitation bubbles. Experimental Thermal and Fluid Science, vol. 32, no. 5, p. 1188-1191, DOI:10.1016/j.expthermflusci.2008.01.006.

[48] Yang, S.H., Jaw, S.Y., Yeh, K.C., (2012). Experimental Study on Generation of Single Cavitation Bubble Collapse Behaviour by a High Speed Camera Record. Gokcek, D.M., (ed.), Mechanical Engineering, InTech, p. 463-482. 
[49] Brujan, E.A., Ikeda, T., Matsumoto, Y. (2012). Shock wave emission from a cloud of bubbles. Soft Materials, vol. 8, p. 5777-5783, DOI:10.1039/ C2SM25379H.

[50] Hansson, I., Kedrinskii, V., Mørch, K.A. (1982). On the dynamics of cavity clusters. Journal of Physics D: Applied Physics, vol. 15, no. 9, p. 1725, DOI:10.1088/0022-3727/15/9/017.

[51] Kumar, S., Brennen, C.E. (1991). Nonlinear effects in the dynamics of clouds of bubbles. The Journal of the Acoustical Society of America, vol. 89, no. 2, p. 707714, DOI:10.1121/1.1894630.

[52] Williams, P.R., Williams, P.M., Brown, S.W.J. (1997). A technique for studying liquid jets formed by cavitation bubble collapse under shockwaves, near a free surface. Journal of Non-Newtonian Fluid Mechanics, vol. 72, no. 1, p. 101-110, DOI:10.1016/ S0377-0257(97)00020-7.

[53] Van Terwisga, T.J.C., Fitzsimmons, P.A., Ziru, L., Jan Foeth, E. (2009). Cavitation Erosion - A review of physical mechanisms and erosion risk models. $7^{\text {th }}$ International Symposium on Cavitation, p. 1-13.

[54] Shaw, S.J., Spelt, P.D.M. (2010). Shock emission from collapsing gas bubbles. Journal of Fluid Mechanics, vol. 646, p. 363, DOI:10.1017/S0022112009993338.

[55] Brujan, E.A., Ikeda, T., Yoshinaka, K., Matsumoto, Y. (2011). The final stage of the collapse of a cloud of bubbles close to a rigid boundary. Ultrasonics Sonochemistry, vol. 18, no. 1, p. 59-64, DOI:10.1016/j.ultsonch.2010.07.004.

[56] Brujan, E.A. (2004). The role of cavitation microjets in the therapeutic applications of ultrasound. Ultrasound in Medicine \& Biology, vol. 30, no. 3, p. 381-387, DOI:10.1016/j.ultasmedbio.2003.10.019.

[57] Barrow, M.S., Bowen, W.R., Hilal, N., Al-Hussany, A., Williams, P.R., Williams, R.L., Wright, C.J. (2003). A study of the tensile properties of liquids in confined spaces using an atomic force microscope. Proceedings of the Royal Society of London. Series A: Mathematical, Physical and Engineering Sciences, vol. 459, no. 2039, p. 2885-2908, DOI:10.1098/ rspa.2003.1128.

[58] Fortes-Patella, R., Challier, G., Reboud, J.L., Archer, A. (2001). Cavitation erosion mechanism: numerical simulations of the interaction between pressure waves and solid boundaries. $4^{\text {th }}$ International Symposium on Cavitation, DOI:CAV2001:sessionA3.006.

[59] Williams, P.R., Williams, P.M., Brown, S.W.J. (1998). A study of liquid jets formed by bubble collapse under shock waves in elastic and Newtonian liquids. Journal of Non-Newtonian Fluid Mechanics, vol. 76, no. 1-3, p. 307-325, DOI:10.1016/S0377-0257(97)00124-9.

[60] Pogodaev, L., Tret'yakov, D. (2009). The reference model of the impact of cavitation erosion on materials. Journal of Machinery Manufacture and Reliability, vol. 38, no. 1, p 51-57, DOI:10.3103/ S1052618809010105.
[61] Thiruvengadam, A. (1963). A Unified Theory of Cavitation Damage. Journal of Basic Engineering, vol. 85, no. 3, p. 365-373, DOI:10.1115/1.3656610.

[62] Standard Test Method for Cavitation Erosion Using Vibratory Apparatus, ASTM Standard G32-98, vol. 03.02 (1998), American Society for Testing and Materials, West Conshohocken, p. 115

[63] García-Atance Fatjó, G., Hadfield, M., Vieillard, C., Sekulic, J. (2009). Early stage cavitation erosion within ceramics - An experimental investigation. Ceramics International, vol. 35, no. 8, p. 3301-3312. DOI:10.1016/j.ceramint.2009.05.020.

[64] Osterman, A., Bachert, B., Širok, B., Dular, M. (2009). Time dependant measurements of cavitation damage. Wear, vol. 266, no. 9-10, p. 945-951, DOI:10.1016/j. wear.2008.12.002.

[65] Franc, J.-P. (2009). Incubation time and cavitation erosion rate of work-hardening materials. Journal of Fluids Engineering, vol. 131, no. 2, 021303 , DOI:10.1115/1.3063646.

[66] Franc, J.-P., Michel, J.M. (2010). Fundamentals of Cavitation, Springer, New York, Boston, Doordrecht, London, Moscow.

[67] Zhou, Y.-K., Hammitt, F.G. (1983). Cavitation erosion incubation period. Wear, vol. 86, no. 2, p. 299-313, DOI:10.1016/0043-1648(83)90168-0.

[68] Fatjo, G.G.A., Hadfield, M., Tabeshfar, K. (2011). Pseudoplastic deformation pits on polished ceramics due to cavitation erosion. Ceramics International, vol. 37, p. 6, p. 1919-1927, DOI:10.1016/j. ceramint.2011.03.043.

[69] Karunamurthy, B., Hadfield, M., Vieillard, C., Morales, G. (2010). Cavitation erosion in silicon nitride: Experimental investigations on the mechanism of material degradation. Tribology International, vol. 43, no. 12, p. 2251-2257, DOI:10.1016/j. triboint.2010.06.012.

[70] Tomlinson, W.J., Kalitsounakis, N., Vekinis, G. (1999). Cavitation erosion of aluminas. Ceramics International, vol. 25, no. 4. p. 331-338, DOI:10.1016/ S0272-8842(98)00043-1.

[71] Lu, J., Zum Gahr, K.-H., Schneider, J. (2008). Microstructural effects on the resistance to cavitation erosion of $\mathrm{ZrO}_{2}$ ceramics in water. Wear, vol. 265 , no. $11-12$, p. $1680-1686$, DOI:10.1016/j. wear.2008.04.028

[72] Momber, A.W. (2003). Cavitation damage to geomaterials in a flowing system. Journal of Materials Science, vol. 38, no. 4, p. 747-757, DOI:10.1023/A:1021800812885.

[73] Grabco, D., Palistrant, N., Shikimaka, O., Zhitaru, R., Rahvalov, V., Zugravescu, D. (2002). Hardness and brittleness of rocks studied by microindentation in combination with the acoustic emission method. $8^{\text {th }}$ European Conference on Nondestructive Testing, p. 17-21.

[74] Momber, A.W. (2004). Wear of rocks by water flow. International Journal of Rock Mechanics and Mining 
Sciences, vol. 41, no. 1, p. 51-68, DOI:10.1016/ S1365-1609(03)00075-3.

[75] Lubarda, V.A., Mastilovic, S. Knap, J. (1996). Brittleductile transition in porous rocks by cap model. Journal of Engineering Mechanics-ASCE, vol. 122, no. 7, p. 633-642, DOI:10.1061/(ASCE)07339399(1996)122:7.

[76] Wang, L.F., Sondi, I., Matijevic, E. (1999). Preparation of uniform needle-like aragonite particles by homogeneous precipitation. Journal of Colloid Interface Science, vol. 218, p. 545-553, DOI:10.1006/ jcis.1999.6463.

[77] Merriman, R.J., Peacor, D.R. (1999). Very low grade metapelites; mineralogy, microfabrics and measuring reaction progress. Frey, M., Robinson, D. (eds.), Lowgrade Metamorphism. Blackwell, Oxford, p. 10-60.

[78] Fatjo, G., Hadfield, M., Vieillard, C., Sekulic, J. (2009). Early stage cavitation erosion within ceramics: an experimental investigation. Ceramics International, vol. 35, no. 8, p. 3301-3312, DOI:10.1016/j.ceramint.2009.05.020.

[79] Dalas, E. (2001). The effect of ultrasonic field on calcium carbonate scale formation. Journal of Crystal Growth, vol. 222, no. 1-2, p. 287-292, DOI:10.1016/ S0022-0248(00)00895-2.

[80] Benzinger, W., Schygulla, U., Jager, M., Schubert, K., (2005). Anti fouling investigations with ultrasound in a micro-structured heat exchanger. $6^{\text {th }}$ International Heat Exchanger Fouling and Cleaning - Challenges and Opportunities Conference, p. 197-201.

[81] Li, H.X., Huai, X.I., Cai, J., Liang, Q. (2009). Experimental research on antiscale and scale removal by ultrasonic cavitation. Journal of Thermal Science, vol. 18, no. 1, p. 65-73, DOI:10.1007/s11630-0090065-x.

[82] Kazi, N., Duffy, G.G., Chen, X.D. (2012). Fouling and fouling mitigation on heated metal surfaces. Desalination, vol. 288, no. 0, p. 126-134, DOI:10.1016/j.desal.2011.12.022.

[83] Feng, D., van Deventer, J.S.J., Aldrich, C. (2006). Ultrasonic defouling of reverse osmosis membranes used to treat wastewater effluents. Separation and Purification Technology, vol. 50, no. 3, p. 318-323, DOI:10.1016/j.seppur.2005.12.005.

[84] Nishida, I. (2004). Precipitation of calcium carbonate by ultrasonic irradiation. Ultrasonics Sonochemistry, vol. 11, no. 6, p. 423-428, DOI:10.1016/j. ultsonch.2003.09.003.

[85] Mihai, M., D. Turtoi, Mateescu, C., Chilibon, I., (2009). Calcium carbonate synthesis in ultrasonic field. Revista De Chimie, vol. 60, no. 6, p. 626-631.

[86] He, M.Z., Forssberg, E., Yanmin, W. MHan, Y,. (2005). Ultrasonication-assisted synthesis of calcium carbonate nanoparticles. Chemical Engineering Communications, vol. 192, no. 10-12, p. 1468-1481, DOI:10.1080/009864490896025.

[87] Santos, R.M., François, D., Mertens, G., Elsen, J., Van Gerven, T. (2012). Ultrasound-intensified mineral
Carbonation. Applied Thermal Engineering. In Press. DOI:10.1016/j.applthermaleng.2012.03.035.

[88] Price, J., Mahon, M.F., Shannon, J., Cooper, C. (2010). Composition of calcium carbonate polymorphs precipitated using ultrasound. Crystal Growth \& Design, vol. 11, no. 1, p. 39-44, DOI:10.1021/ cg901240n.

[89] Marković, S., Mitrić, M., Starčecić, G., Uskoković, D. (2008). Ultrasonic de-agglomeration of barium titanate powder. Ultrasonics Sonochemistry, vol. 15, no. 1, p. 16-20, DOI:10.1016/j.ultsonch.2007.07.008.

[90] Kojima, Y., Yamaguchi, K., Nishimiya, N. (2010). Effect of amplitude and frequency of ultrasonic irradiation on morphological characteristics control of calcium carbonate. Ultrasonics Sonochemistry, vol. 17, no. 3, p. 617-620, DOI:10.1016/j. ultsonch.2009.10.020.

[91] Mateescu, C.D., Sarbu, C., Isopescu, R., Dumitrescu, O., Ghica, D. (2011). Sonocrystallization of calcium carbonate metastable polymorphs in alcoholic solutions as reaction media. 18th International Symposium on Industrial Crystallization, p. 4.

[92] Santos, R., Ceulemans, P., François, D., Van Gerven, T. (2011). Ultrasound-enhanced mineral carbonation. The $3^{\text {rd }}$ European Process Intensification Conference, p. 108-116.

[93] Sollars, R., Beitelman, A. (2011). Cavitation-resistant coatings for hydropower turbines. US Army Corps of Engineers, Engineer Research and Development Center, Construction Engineering Research Laboratory, Portland, p. 1-67.

[94] Schramm, B., Dwars, A., Kühl, A. (2005). Do coatings protect against corrosion and wear? World Pumps, vol. 470, p. 32-38, DOI:10.1016/S02621762(05)70818-X.

[95] Buravova, S., Gordopolov, Y. (2010). Bubbleinduced cavitation effect upon solid surfaces. Technical Physics Letters, vol. 36, no. 8, p. 717-719, DOI:10.1134/S1063785010080110.

[96] Chernega, S. (1998). On the mechanism of deterioration of composite eutectic coatings by cavitation. Powder Metallurgy and Metal Ceramics, vol. 37, no. 7, p. 373-378, DOI:10.1007/BF02676018.

[97] Krella, A., Czyzniewski A. (2007). Influence of the substrate hardness on the cavitation erosion resistance of TiN coating. Wear, vol. 263, no 1-6, p. 395-401, DOI:10.1016/j.wear.2007.02.003.

[98] Krella, A. (2011). An experimental parameter of cavitation erosion resistance for TiN coatings. Wear, vol. 270, no. 3-4, p. 252-257, DOI:10.1016/j. wear.2010.10.065.

[99] Paik, B.-G., Kim, K.-S., Kim, K.-Y., Ahn, J.-W., Kim, T.-G., Kim, K.-R., Jang, Y.-H., Lee, S.-U. (2011). Test method of cavitation erosion for marine coatings with low hardness. Ocean Engineering, vol. 38, no. 13, p. 1495-1502, DOI:10.1016/j.oceaneng.2011.07.008. 
[100] Tan, H. (2008). Spalling and fragmentation Part 1, p. 1-5, from http://imechanica.org, accessed on 2012-0201

[101] Ledrappier, F., Langlade, C., Gachon, Y., Vannes, B. (2008). Blistering and spalling of thin hard coatings submitted to repeated impacts. Surface and Coatings Technology, vol. 202, no. 9, p. 1789-1796, DOI:10.1016/j.surfcoat.2007.07.107.

[102] Mishnaevsky, L.L., Gross, D. (2004). Micromechanisms and mechanics of damage and fracture in thin film/substrate systems. International Applied Mechanics, vol. 40, no. 2, p. 140-155, DOI:10.1023/B:INAM.0000028592.55112.b9.

[103] Loh, R.L., Rossington, C., Evans, A.G. (1986). Laser Technique for Evaluating Spall Resistance of Brittle Coatings. Journal of the American Ceramic Society, vol. 69, no. 2, p. 139-142, DOI:10.1111/j.1151-2916.1986.tb04718.x.

[104] Zhou, A.-D., Yang, H.-X., Zhang, Z.-B. (2005). Application of Ultrasonic in Anti-scaling. Applied Chemical Industry, vol. 34, p. 659-661.

[105] Ichida, Y., Sato, R., Morimoto, Y., Kobayashi, K., (2005). Material removal mechanisms in non-contact ultrasonic abrasive machining. Wear, vol. 258, no. 1-4, p. 107-114, DOI:10.1016/j.wear.2004.05.016.

[106] Chen, H., Wang, J., Chen, D. (2009). Cavitation damages on solid surfaces in suspensions containing spherical and irregular microparticles. Wear, vol. 266, no. 1-2, p. 345-348, DOI:10.1016/j.wear.2008.05.010.

[107] Zeiger, B.W., Suslick, K.S. (2011). Sonofragmentation of molecular crystals. Journal of the American Chemical Society, vol. 133, no. 37, p. 14530-14533, DOI:10.1021/ja205867f.
[108] Stephanis, C.G., Hatiris, J.G., Mourmouras, D.E. (1997). The process (mechanism) of erosion of soluble brittle materials caused by cavitation. Ultrasonics Sonochemistry, vol. 4, no. 3, p. 269-271, DOI:10.1016/S1350-4177(96)00040-5.

[109] Viten'ko, T., Gumnitskii, Y. (2006). Mass transfer during dissolution of solids using hydrodynamic cavitation devices. Theoretical Foundations of Chemical Engineering, vol. 40, no. 6, p. 598-603, DOI:10.1134/S0040579506060078.

[110] Ohno, S., Kadono, T., Ishibashi, K., Kawaragi, K., Sugita, S., Nakamura, E., Matsui, T. (2008). Direct measurements of impact devolatilization of calcite using a laser gun. Geophysical Research Letters, vol. 35, no. 13, p. L13202, DOI:10.1029/2008GL033796.

[111] Boslough, M.B., Ahrens, T.J., Vizgirda, J., Becker, R.H., Epstein, S. (1982). Shock-induced devolatilization of calcite. Earth and Planetary Science Letters, vol. 61, no. 1, p. 166-170, DOI:10.1016/0012-821X(82)90049-8.

[112] Grady, D.E. (1976). Processes Occurring in Shock Wave Compression of Rocks And Minerals, Sandia Laboratories. Albuquerque, p. 1-83.

[113] Gupta, S.C., Love, S.G., Ahrens, T.J. (2002). Shock temperature in calcite (CaCO3) at 95-160 GPa. Earth and Planetary Science Letters, vol. 201, no. 1, p. 1-12, DOI:10.1016/S0012-821X(02)00685-4.

[114] Spray, J.G. (1999). Shocking rocks by cavitation and bubble implosion. Geology, vol. 27, no. 8, p. 695-698, DOI:10.1130/0091-7613(1999)027<0695:SRBCAB> 2.3.CO;2. 